\title{
Optimising Potable Water Pumping Operations in Small-Scale Gold Mining Environments in Ghana Using Daboase Headworks as a Case Study
}

\author{
Christian Kwaku Amuzuvi ${ }^{1}$, , Joseph Kwarteng ${ }^{2}$, Emmanuel Aboah $^{3}$ \\ ${ }^{1}$ Department of Electrical and Electronic Engineering, University of Mines and Technology, Tarkwa, Ghana \\ ${ }^{2}$ Ghana Water Company Limited, Daboase, Ghana \\ ${ }^{3}$ Golden Star Resources Limited, Prestea Underground Mine, Prestea, Ghana
}

Email address:

ckamuzuvi@umat.edu.gh (C. K. Amuzuvi), ckamuzuvi2000@yahoo.com (C. K. Amuzuvi)

${ }^{*}$ Corresponding author

\section{To cite this article:}

Christian Kwaku Amuzuvi, Joseph Kwarteng, Emmanuel Aboah. Optimising Potable Water Pumping Operations in Small-Scale Gold Mining Environments in Ghana Using Daboase Headworks as a Case Study. Engineering and Applied Sciences. Vol. 4, No. 6, 2019 , pp. 154-163. doi: $10.11648 /$ j.eas.20190406.14

Received: November 18, 2019; Accepted: December 2, 2019; Published: December 7, 2019

\begin{abstract}
This paper assesses the challenges facing the optimisation of potable water pumping operations in small scale gold mining environments in Ghana using the Daboase headworks as a case study. The paper reviews the level of water pollution and its negative impact on alternating current motors and other electrical fittings at the Daboase headwork. The method of data collection used for the paper were questionnaires, interviews, cluster sampling and systematic sampling. Four sampling operation components were used, namely: selection of sampling stations, selection of water quality parameters, sampling frequency, and data collection and analysis methods. The paper focuses on the substantial reduction in pump energy consumption, operational and maintenance cost and the optimisation of potable water pumping operation systems in conclusion. The study proposes an upgrade of electrical controls with new state of the art control panels and a multi-level pumping system. Finally, it recommends a modelled space vector pulse width modulation variable speed drive, which has a greater overall performance and higher efficiency, less switching losses and greater power factor, which minimises the cost of operation, maintenance and equipment breakdown as well as optimising productivity of the Daboase headworks.
\end{abstract}

Keywords: Space Vector Pulse Width Modulation, Pumping Systems, Electric Drives, Headworks

\section{Introduction}

Small-scale alluvial gold mining is largely a poverty driven activity, typically practiced in the poorest and most remote rural areas of a country by a largely itinerant, poorly educated populace with few employment alternatives [1], until the current use of heavy machinery in the catchment area. Mineral development processes disturb the soil, rock and river courses. In the case of gold prospecting in the Daboase area, open pits and waste impoundments are rampant. In the absence of adequate prevention and control strategies, erosion of the exposed earth carries substantial amounts of sediment into streams and other rivers, which eventually end up in the main river where excessive sediments have clogged riverbeds and watershed [2]. The River Pra, which serves as the main source of water treatment by the Ghana Water Company Limited to the Sekondi-Takoradi Metropolitan Area, is polluted by illegal alluvial gold mining activities.

The negative impact of artisanal small-scale gold mining activities has affected the optimisation of potable water pumping operations at the Daboase water treatment plant in Ghana. This has resulted in the decline of raw water quality, increase in the operating cost of production and the concomitant pumping system problems such as pump cavitation and poor flow control. Substantial reductions in pump energy, maintenance and replacement costs are also major concerns addressed in this research.

\section{Materials and Methods}


The materials used for this work are literature, published materials from conference proceedings, and journals from the internet using search engines from the world of science and technology. MATLAB Simulink software was used for the analysis and design of the optimal drive for operation.

\subsection{Types of Pumps Used at the Site}

Generally, two types of pumps are used for potable water pumping applications at the existing treatment plant namely: dynamic and displacement pumps. Dynamic pumps are used in conditions where high volumes of water are required and a change in flow not important [3]. As the discharge pressure on a dynamic pump is increased, the quantity of water pumped is reduced. One type of dynamic pump is the centrifugal pump, which is the most common pump used in water systems [4]. At the pumping station, the vertical wet pumps are located at the low lift station or intake point with the column pipes extending down into the suction well of the raw water abstraction point. Displacement pumps on the other hand are pumps used in conditions where relatively low but precise volumes of water is required. The displacement pump will not change the volume with a change in the discharge pressure [5]. The most common positive displacement pump is the diaphragm pump used in the pumping of chlorine and alum solutions.

\subsection{The Effects of Alluvial Mining on Electrical Installations}

\section{Undesirable Operations}

Figure 1 [6] shows the structure of the vertical wet pump installed at the intake point of the Daboase headworks. The minimum submergence above the bell mouth or foot valve is necessary so as to prevent air entry into the suction of the pump. This gives rise to vortex phenomenon causing excessive vibration, overloading of bearings, reduction in discharge and efficiency. As a useful guide, the lowest permissible water level is marked on the water level indicator [6]. The pump must never be operated at head higher than the maximum recommended. Such operation results in excessive recirculation in the pump, overheating of the water and the pump. Also, the radial reaction on the pump shaft increases, causing excessive unbalanced forces on the shaft, which may cause failure of the pump shaft [7]. As a useful guide, an appropriate marking on the pressure gauge is made.

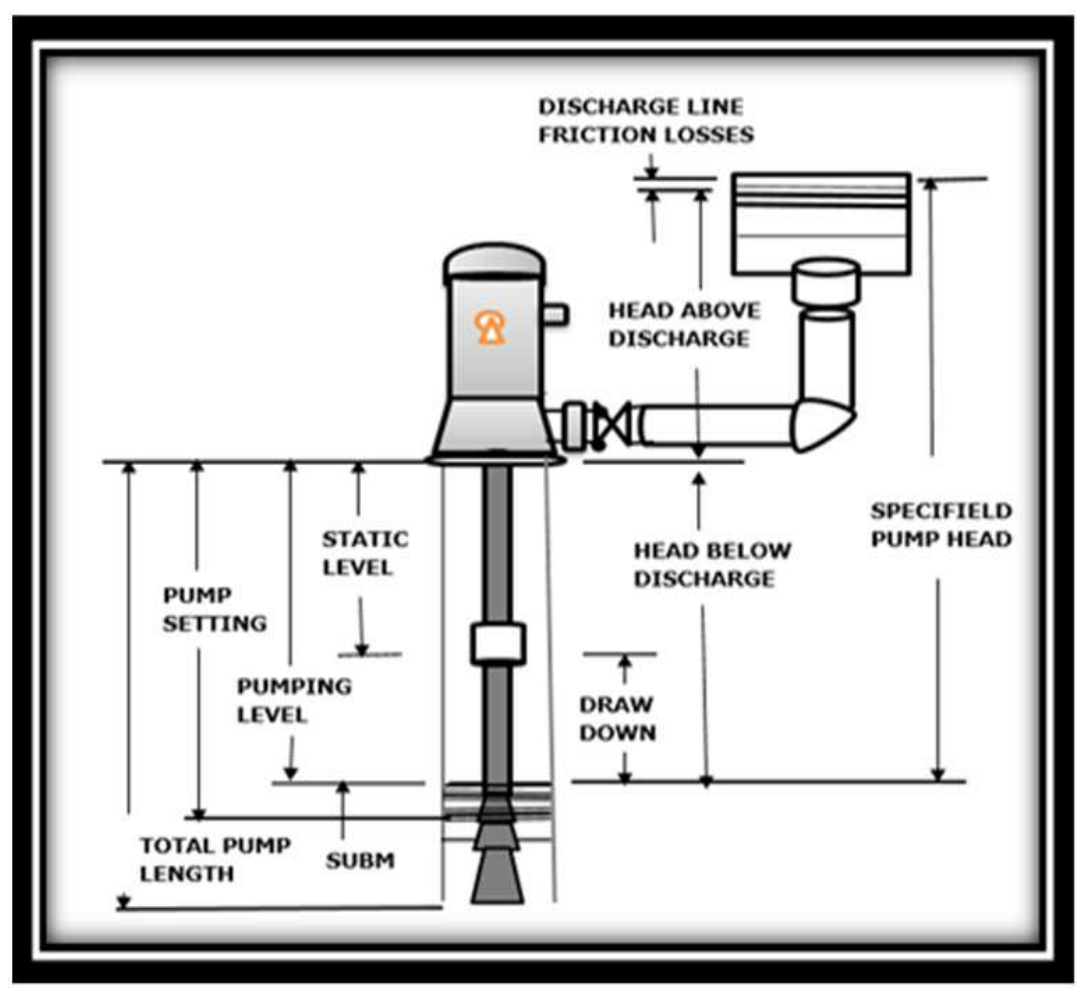

Figure 1. The Structure of the Vertical Wet Pump.

\subsection{Economics of Improving Pumping Systems}

Pumping systems are often critical to plant operations. In fact, about 27 percent of all energy consumed by motor driven equipment in manufacturing facilities are for pump operation. In many industrial applications, such as petrochemical plants, pumps directly support production processes and run as often as, or longer than any other equipment at the facility. With such high run times, the energy consumed by many pumping systems often result in substantial annual costs [8].

Operating costs of the existing pumping systems at the Daboase Headworks includes energy, maintenance and operational costs. Of these three variables, energy costs are relatively easy to determine with simple measurements.

Requirements for Optimising Productivity

The operation of a pumping station as very important in achieving the tasks of the station [9]. The main task is to maintain a suitable water volume in the reservoir and supply 
the demands. With the operation scheduling optimised, a remarkable reduction of the operation cost can be achieved while no change is needed with the physical elements, such as pumps and civil infrastructures [10].

There are mainly two classes of operational costs for a pumping station. One is the energy cost, and the other is the maintenance cost. The maintenance cost, relates to the wear and tear of the rotating equipment, and it is difficult to be quantified. However, it is true that the maintenance cost increase when the number of pumps switched on increases. A simple assumption is that; the maintenance cost is proportional to the number of pumps switched on [11].

\subsection{The Study Area}

Wassa East District is located at the South-Eastern end of the Western Region in Ghana. It is bounded to the North-East and South-East by the Twifo Hemang Lower Denkyira and Komenda Edina Equafo Abrem districts. The district has large deposits of gold, traces of iron and kaolin, coupled with two large forest reserves namely: Subri river forest reserve and Pra Suhyen reserve $[12,13]$. The water treatment plant, which is located 500 metres away from the Daboase town is known as the Daboase headworks.

Power Supply to the Study Area

The headworks receive its bulk supply of power from the Electricity Company of Ghana (ECG) at the Ketan Substation, Takoradi. For reliability and stability purposes, two separate circuits are given to the station namely: circuit 3 and circuit 4 , with two separate transformers with rated power of $2.5 \mathrm{MVA}$ or $2500 \mathrm{kVA}$, and voltage of $33 \mathrm{kV}$ with stepdown voltage of $3.2 \mathrm{kV}$. The utilised power to the treatment plant is $3.2 \mathrm{kV}$. The other transformer has a rated power of $2.5 \mathrm{MVA}, 33 \mathrm{kV} / 11 \mathrm{kV}$ used for the distribution system.

The rated voltage used at the Bosomase intake, one of the substations at the Daboase Headworks is 420 volts with $355 \mathrm{~kW}$ motor. The starting torque of the pumps is relatively high due to the mass per unit volume of water pumped, which has serious impact on the electrical controls. This sometimes chars the control panel components. Figure 2 shows a charred control panel.
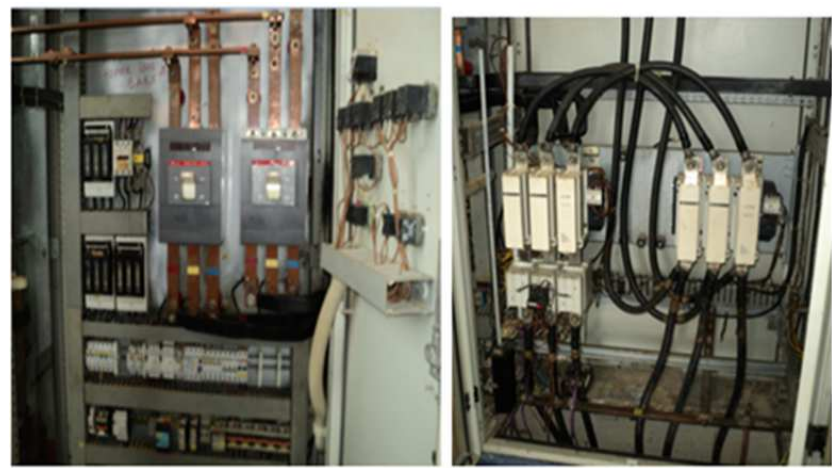

Figure 2. Charred Electrical Installation

The charred electrical components and insulation cables shown in the Figure 2 came about as a result of continuous overheating due to the maximum pump set stress. The excessive increase in temperature of the cables and other electrical fittings under the existing working condition generates copper losses in the conductor, which is equal to $I^{2} \mathrm{R}$; losses in the dielectric strength of the cables and the wires; and losses in other electrical fittings in the control panel, which eventually deteriorate the electrical motor windings.

Figures 3 and 4 depict the repercussion of illegal alluvial gold mining at the Daboase intake points and its negative impacts on the pumps equipment. The existing pump set, electrical control systems and switches that control the AC motors must be replaced with modern retrofitting equipment.

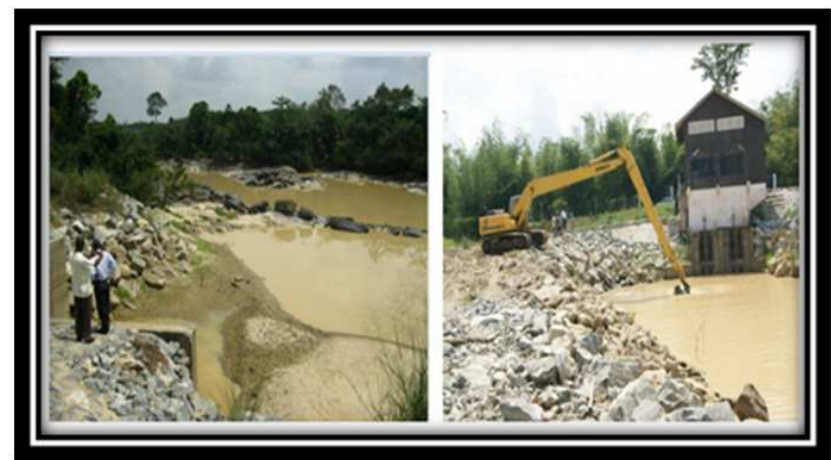

Figure 3. Discoloured Pra River De-silted at Daboase Intake Points.

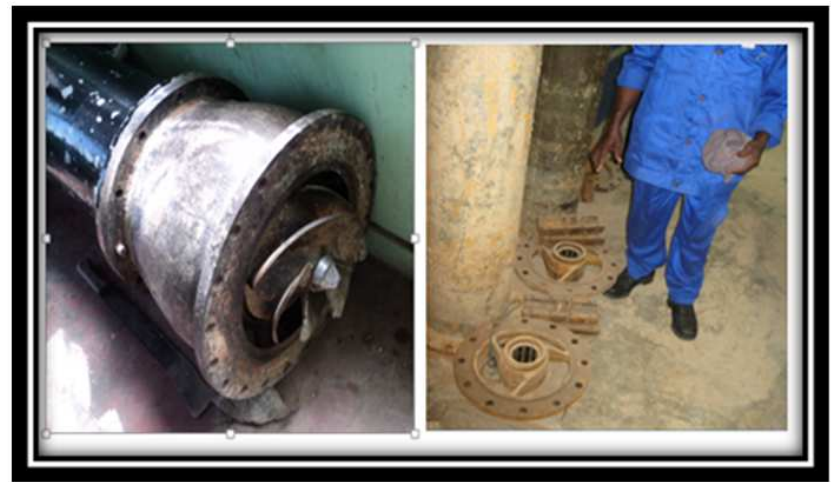

Figure 4. The Impacts of Illegal Mining on Pump Equipment.

\section{Results and Discussion}

\subsection{Proposed Solutions}

The proposed solutions of this research work mainly include; an upgrade of the electrical control panel and the use of a modelled space vector pulse width modulation (SVPWM) variable frequency drive.

\subsubsection{Upgrading the Electrical Control Panel}

In line with the aims of this research, the study proposed the upgrade of electrical controls with new state of the art control panel and retrofitting, which gives the study area reliability and easy use of new equipment at a fractional cost.

Modern Human Machine Interface (HMI) technology stores machine parameters, which could save thousands of dollars in setup and changeover time can be displayed with alarm conditions making troubleshooting and service easier. Replacing older, unreliable control systems with upgraded 
control system can be more cost effective than just replacing the existing old parts of the station.

\subsubsection{Variable Frequency Drives (VFD)}

The Variable Frequency Drive (VFD) is an adjustable-speed drive that is used to control the speed of an AC motor. In order to control the motor's rotational speed, a VFD is used to control the frequency of the electrical power supplied to it. Adding a VFD to an application allows the motor speed to be adjusted in accordance with the motor's load, ultimately saving energy. Figure 5 shows the schematic diagram of the proposed variable speed drive.

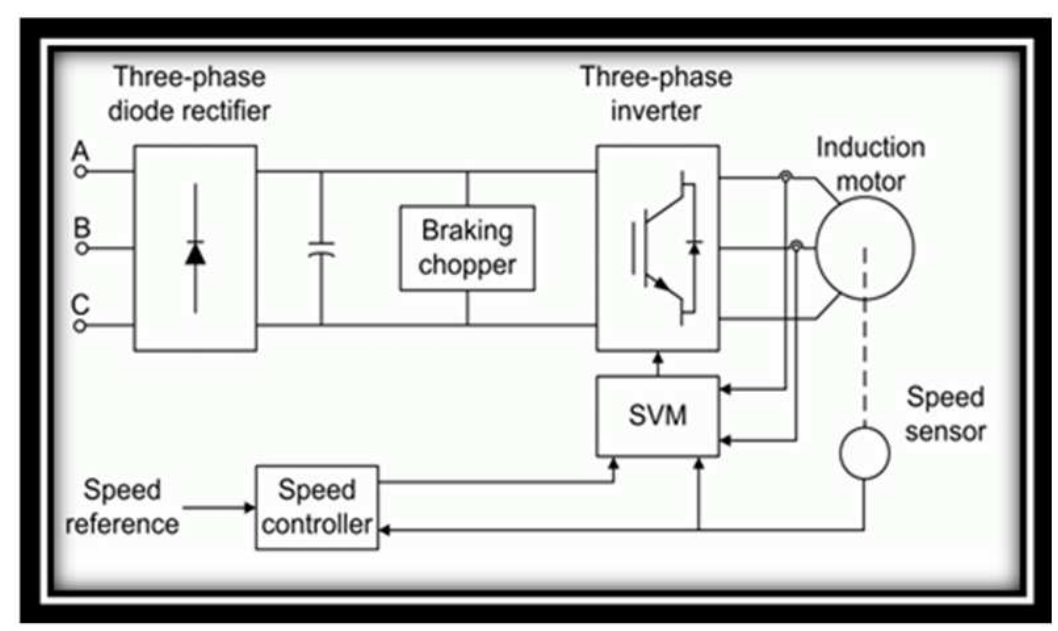

Figure 5. Schematic Diagram of the Proposed Variable Speed Drive.

\subsubsection{Variable Frequency Drive for Constant Pressure Water Supply}

In water supply system, constant pressure water supply refers to the control mode which controls the outlet pressure within the setting value by detecting the pipe and network pressure when the water amount in the pipe and network changes [14]. Usually, when selecting water pump, its rated flow is bigger than the actual flow, and the flow varies a lot when in use. For example, in water supply system, the water consumption between day and night varies a lot. The valve regulation mode is commonly used [15]. However, it is regulated by increasing resistance manually that result in a lot of waste in electricity and high maintenance requirement. Variable frequency $\mathrm{AC}$ drive is introduced with built-in Proportional Integral and Derivative control to perform the automatic constant pressure water supply for saving energy. Figure 6 shows the wiring circuit diagram of the VFD.

As illustrated in the wiring diagram, connections are made with air switch, leakage switch and power supply. After completing the wiring detection, the air switch is turned on and the variable frequency drive is connected. YTZ-150 potentiometer remote manometer was selected and installed on the outlet pipe of the water pump. The manometer is applied in regular manometer working condition, which could not only measure directly the value of pressure, but also outputs corresponding to the electrical signals to the remote controller.

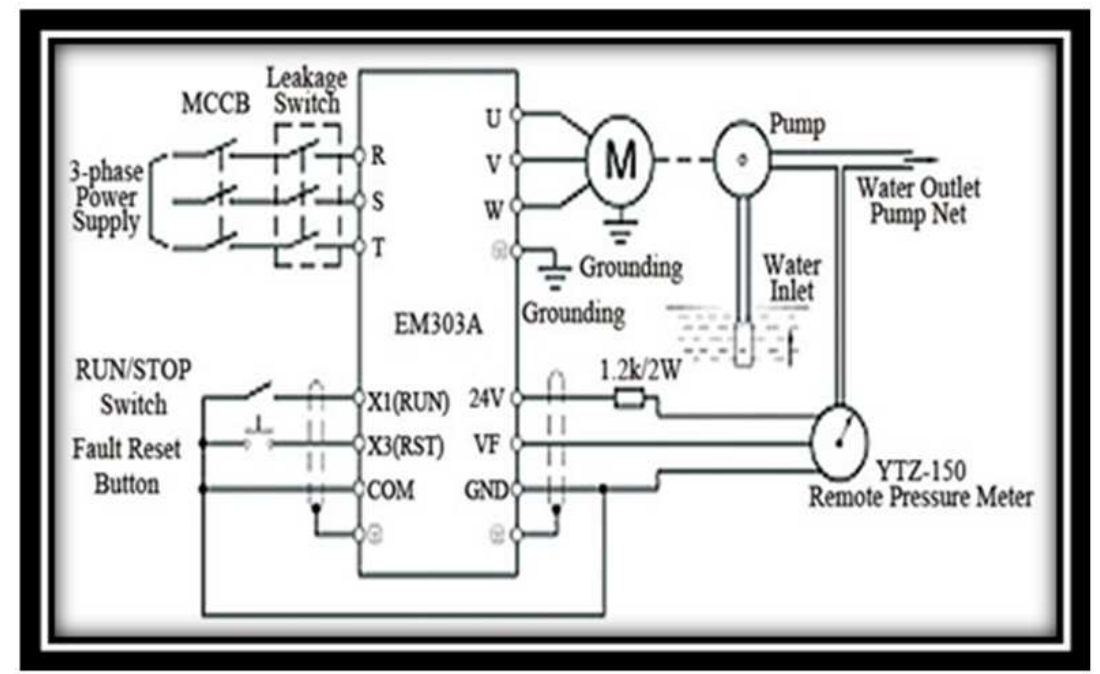

Figure 6. VFD for Constant Pressure Water Supply Wiring. 


\subsubsection{Working Principle of the Variable Frequency Drive}

When complete voltage is applied to an AC motor, it accelerates the load and drops torque initially, keeping current especially high until the motor reaches full speed [16]. The Variable Frequency Drive operates differently; it eliminates excessive current, increasing voltage and frequency in a controlled manner as the motor starts. This allows the AC motor to generate up to $150 \%$ of its rated torque, which could potentially be generated from the start to full speed, without wasting energy. The VFD converts power through three different stages. First, AC power is converted to DC power; second the switching on and off of the power transistors; third the generation of a voltage waveform at the desired frequency. This waveform then adjusts output voltage according to the preferred designated value.

\subsection{Customised Solution for Pumps}

In order to make the pumps suitable for even more aggressive liquid application, it is recommended that the pump systems be redesigned. This will enable some of the vital and vulnerable pump parts to handle difficult liquids or stand up to particularly demanding operating conditions.

The modular concept of the pump range makes it possible to put together a specialised pump for any particular application by selecting the modules best suited for the job from the existing pump at the station under study. Table 1 shows the existing pump set parameters that requires modular approach.
Table 1. Existing Factors of Pump Parameters at Daboase and Bosomase Intake Points.

\begin{tabular}{|c|c|c|}
\hline \multicolumn{3}{|c|}{ Existing Factors of Pump Parameters at Bosomase Intake } \\
\hline $\mathrm{SN}$ & Sihi Pump Type & \\
\hline 1 & Capacity of the pump & $\mathrm{Q}=1200 \mathrm{~m}^{3} / \mathrm{h}$ \\
\hline 2 & Head of the pump & $\mathrm{H}=71 \mathrm{~m}$ \\
\hline 3 & Rated pump power & $\mathrm{kW}=355 \mathrm{~kW}$ \\
\hline 4 & Supply voltage & $\mathrm{Vs}=415$ volts \\
\hline 5 & Current & $\mathrm{Amp}=595 \mathrm{~A}$ \\
\hline 6 & Frequency & $\mathrm{Hz}=50 \mathrm{~Hz}$ \\
\hline 7 & Speed & $\mathrm{Nr}=1480 \mathrm{rpm}$ \\
\hline \multirow[t]{2}{*}{8} & Torque & $\operatorname{Tr}=8 \mathrm{Nm}$ \\
\hline & Pipe Size & \\
\hline 9 & Suction diameter & $\mathrm{D}_{\mathrm{N}}=300 \mathrm{~mm}$ \\
\hline 10 & Discharge diameter & $\mathrm{D}_{\mathrm{N}}=400 \mathrm{~mm}$ \\
\hline 11 & Pressure nominal & $\mathrm{P}_{\mathrm{N}}=16 \mathrm{bar}$ \\
\hline \multirow[t]{2}{*}{12} & Length of the pipe to treatment centre & $\mathrm{L}=24 \mathrm{~km}$ \\
\hline & Existing Factors of Pump Parameters a & aboase Intake \\
\hline 13 & Capacity of the pump & $\mathrm{Q}=590 \mathrm{~m}^{3} / \mathrm{h}$ \\
\hline 14 & Pump Head & $\mathrm{H}=21 \mathrm{~m}$ \\
\hline 15 & Rated pump power & $\mathrm{kW}=55 \mathrm{~kW}$ \\
\hline 16 & Supply voltage & $\mathrm{Vs}=420$ volts \\
\hline 17 & Rated Current & $\mathrm{A}=106 \mathrm{~A}$ \\
\hline
\end{tabular}

The understanding of the above factors in Table 1 gives the vendors the necessary knowledge to select the right pump for abstraction of the raw water and the right slurry pumps to pump out accumulated slurry from time to time in the intake sumps.

The existing pump motors available requires configurations to meet the demands of the pumping environment and/or the pumped liquid itself. Figure 7 shows a MATLAB schematic diagram of the proposed pump solution for the study area.

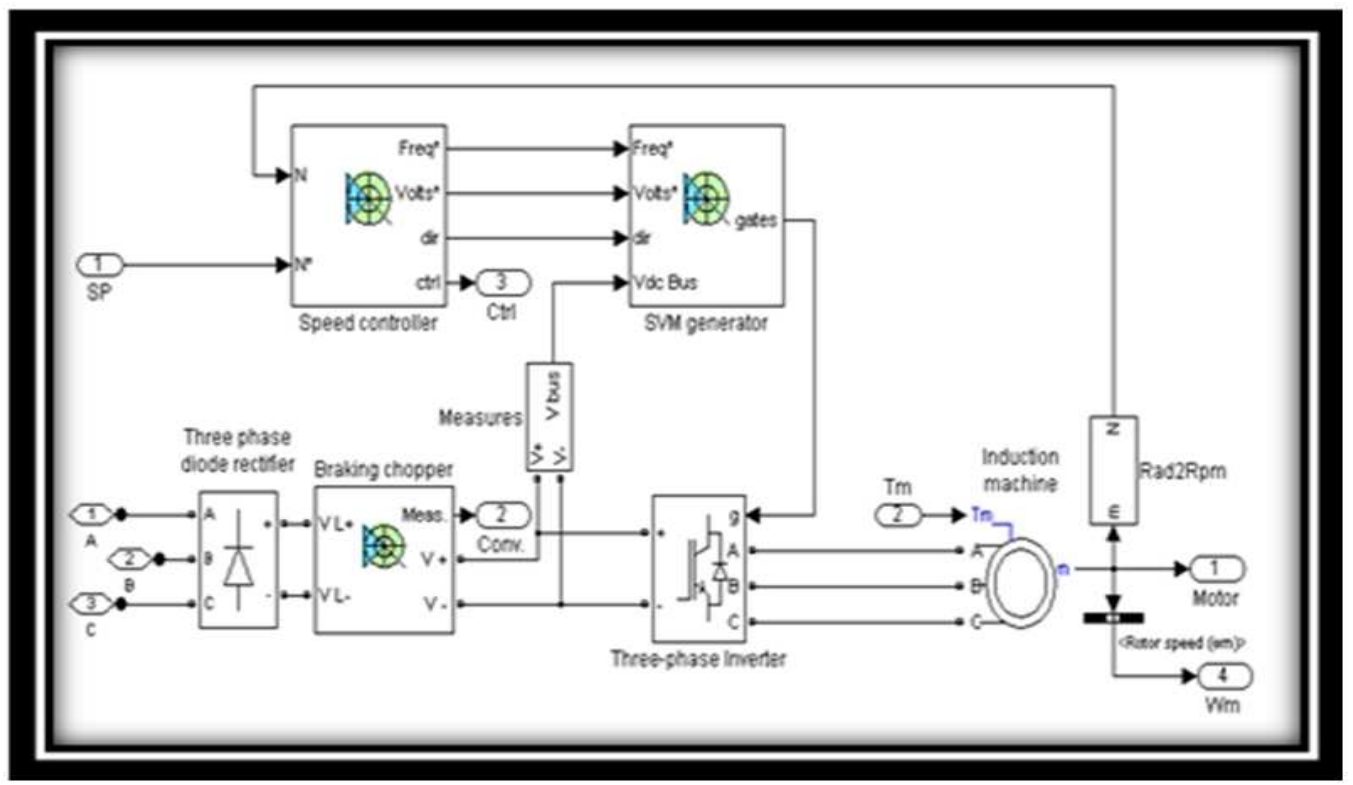

Figure 7. MATLAB Schematic Diagram of the Proposed Solution.

The benefits of this customised design for the proposed pump motor solutions are as follows:

A. Low speed, to be obtained e.g.:

i.) Gentle handling of the liquid;

ii.) Pumping at low Net Positive Suction Head (NPSH) level; and

iii.)Reduced noise emission.

B. The advanced control can be measured and adapted to special applications, e.g.:

i.) Extended protection of pump and drive; 
ii.) Pump performance curve adjusted to match individual applications; and

iii.)The standard motor has built-in motor protection, pump monitoring, and on-board regulator and sensor supply for control pump running process.

\subsection{Data Analysis of the Discoloured Raw Water and the Turbidity Sampling}

The result presented in Figure 8 shows the data analysis of the discoloured raw water and the high turbidity collected for the past ten years.

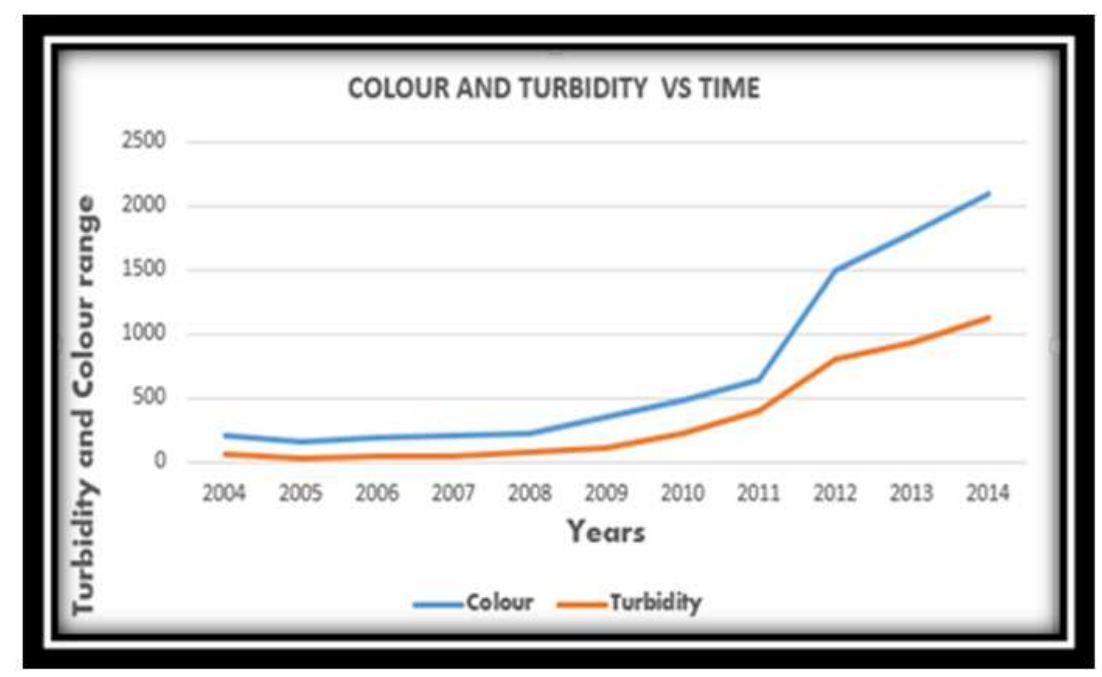

Figure 8. Trends of Colour and Turbidity Over the Years.

The result indicates that, from the year 2004 and beyond, the activities of illegal miners have been increasing, hence the increase in the colour and turbidity of the water with its attendant repercussion on the pump equipment and the pump motors.

\subsection{Simulation Results from Linear Programming Excel Solver}

A series of simulations were performed to evaluate the maintenance cost, operational cost and pump energy consumption using mathematical model equations. Figure 9 shows the optimised graph with the average and target value.

The data analysis of maintenance cost from Figure 9 shows the maintenance cost incurred every month, which exceeds the average target set. This indicates that, repairs and replacement costs are relatively high, and as such, the plant can be run within optimised possible values to minimise cost. Significant cost reduction cannot be achieved without the company modifying its current maintenance philosophies and investing in technology necessary to ensure success.

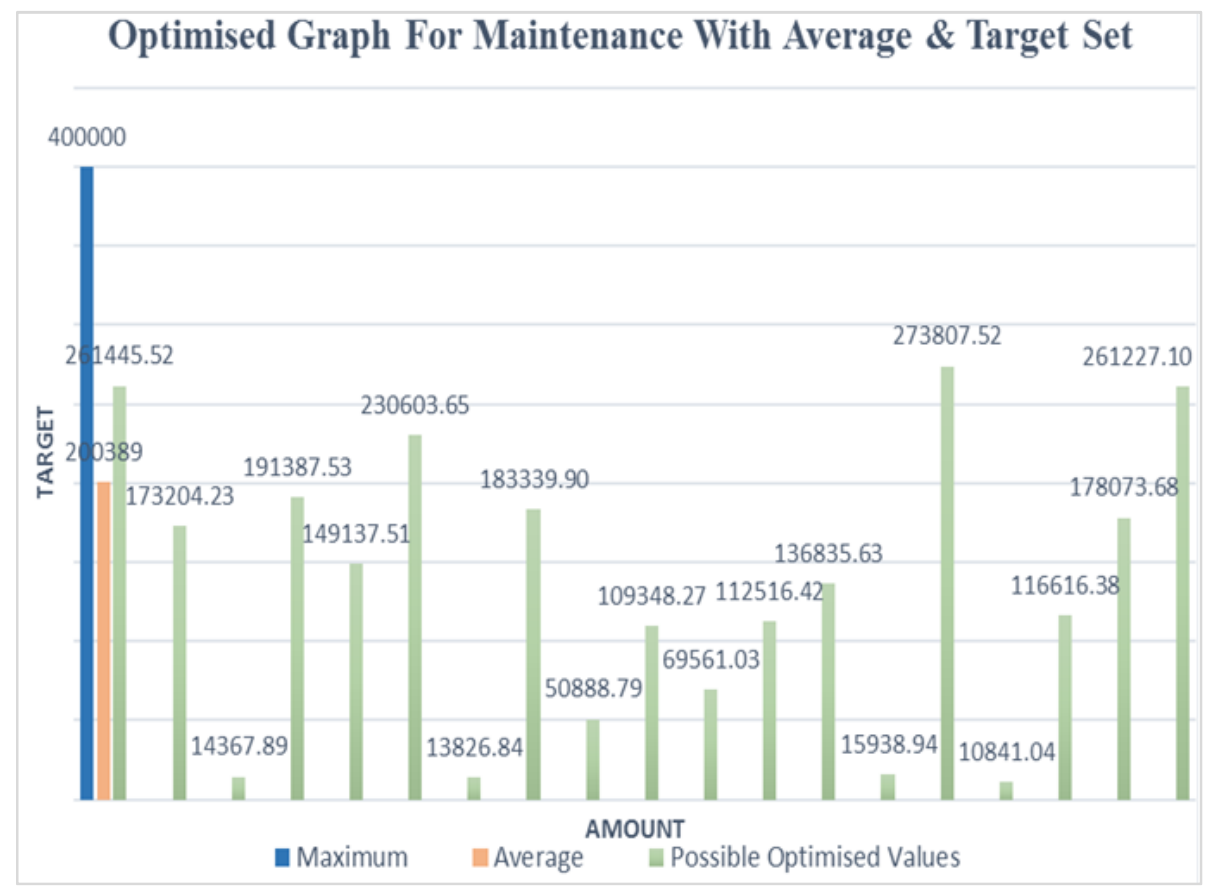

Figure 9. Optimised Graph for Maintenance with Average and Target Set. 


\subsection{The Faulty Equipment and Frequency of Repair}

The graph in Figure 10 indicates the output, which shows that, to minimise unscheduled downtime, basic system maintenance has to be performed at predetermined intervals. The factors that weigh in setting these schedules includes the cost of downtime, the cost and risk of catastrophic failures, and the expected mean time between repairs for motors, bearings, seals, and the availability of backup equipment.

The dotted lines of the graph show the linear faults forecast, which indicates the decline in faults and breakdown maintenance, achieved as a result of preventive maintenance schedules.

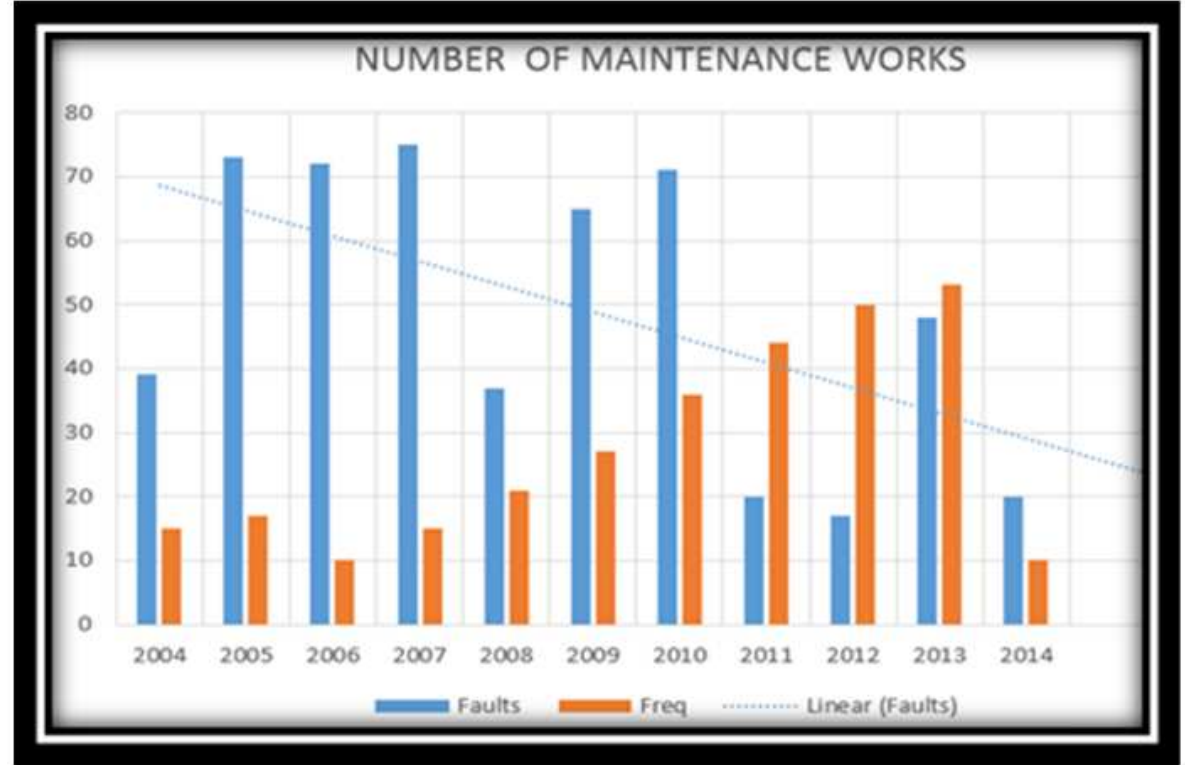

Figure 10. The Trend of Maintenance Works.

\subsection{Simulation Results}

\subsubsection{The Implementation of Fixed Speed Motor}

Figure 11 shows a MATLAB Simulink diagram of a fixed speed motor at the existing plant of the study area. This method used ball valves and globe valves to control the flow and the pressure of the water from the pump as well as reduce water hammer during shutdown. This technique does not only waste a tremendous amount of energy, it also wears out the equipment.

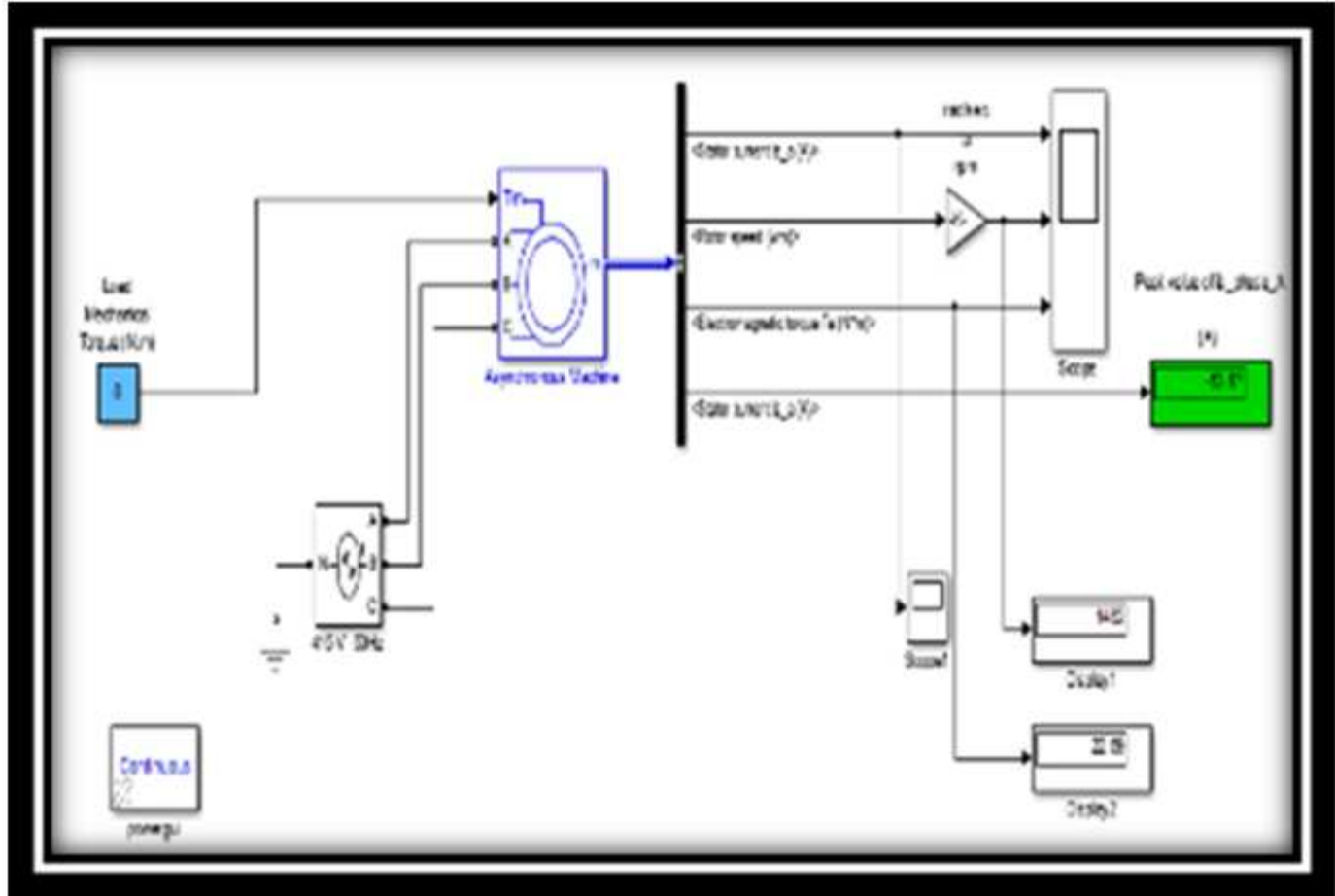

Figure 11. MATLAB Simulink Diagram of Fixed Speed Control Circuit. 
Figure 12 depicts the simulation result for the fixed speed motoring drive. The response of the Simulink model for the fixed speed motor control is presented in Figure 12, which indicates that the initial stator current is so high, coupled with high starting torque as the speed accelerates gradually. The acceleration torque developed to overcome the mechanical inertia and change its speed is given as:

$$
T=J \frac{d w_{r}}{d t}
$$

where, $J=$ moment of inertia .

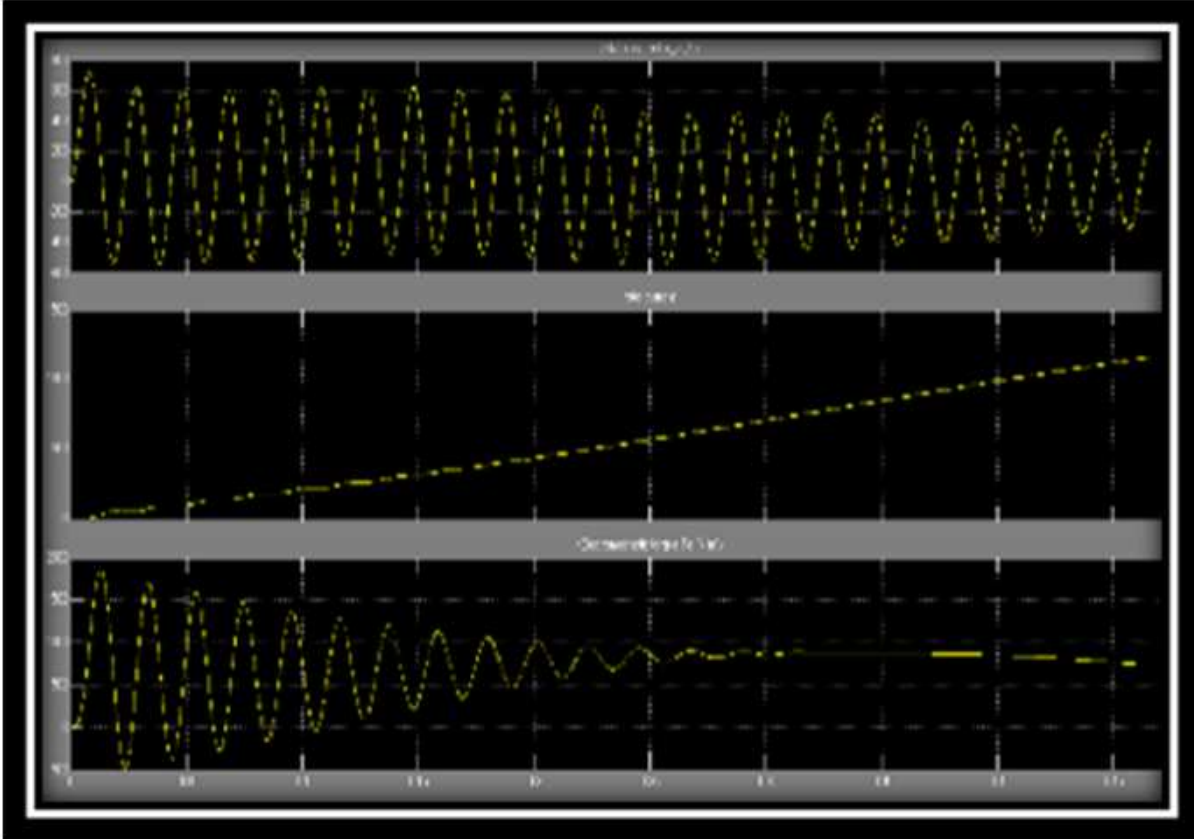

Figure 12. Simulation Results for Fixed Motor Control.

\subsubsection{The Implementation of SVPWM Variable Speed Drive}

The use of the modelled SVPWM variable speed drives for flow and pressure control of electric motor pump results in significant energy savings and a reduction of life-cycle costs. In addition, the variable speed drive provides soft starting/stopping features, which improve system reliability and extend the lifetime of motors.

The principle of space vector modulation is based on the application of space vector as shown in Figure 13.

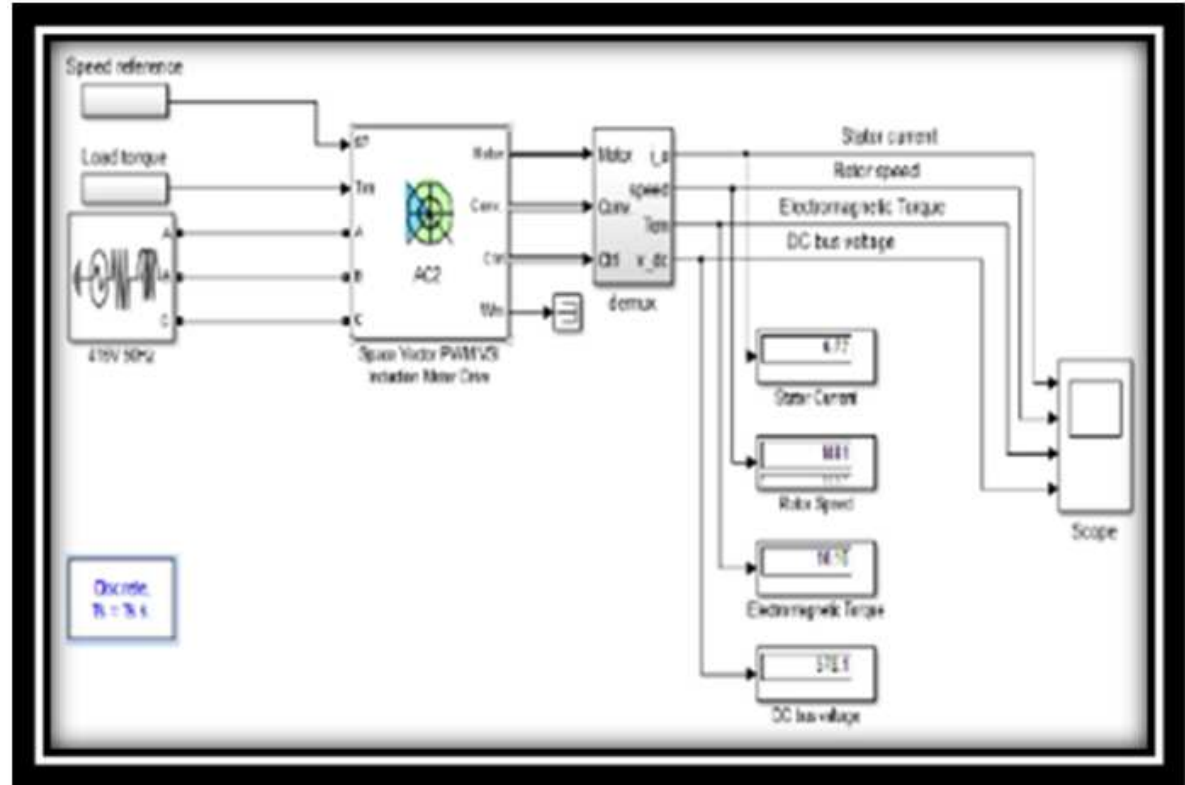

Figure 13. The Implementation of SVPWM Variable Speed Drive. 
The first step in this process is to convert AC supply voltage into DC by the use of rectifier and smoothing using filter capacitors to remove DC voltage ripples. This section of VFD is referred to as the DC link. The DC voltage is then converted back into AC by the use of power electronic devices such as insulated gate bipolar transistors using a technique called pulse width modulation (PWM). Figure 14 shows the simulation results of the modelled SVPWM VFD.

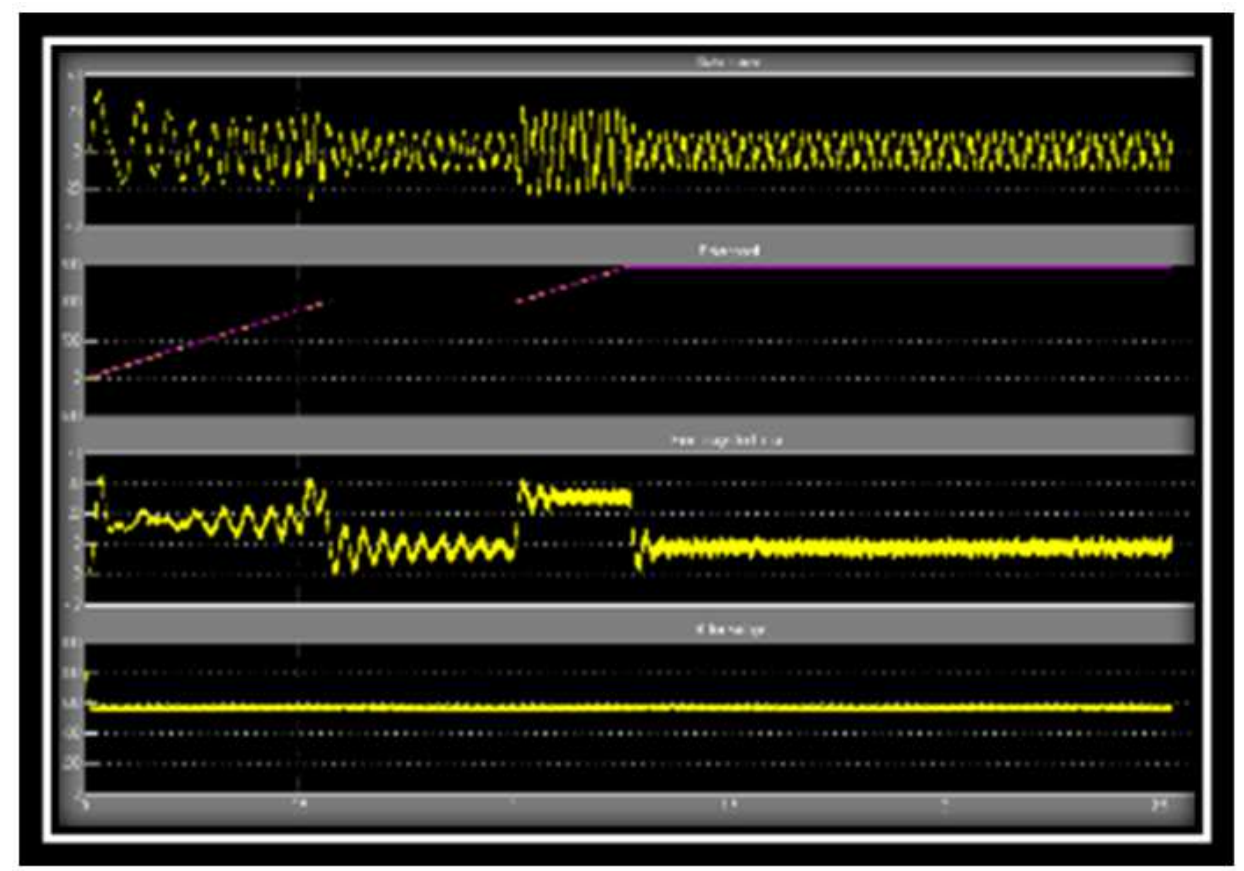

Figure 14. Simulation Result for Implementation of Variable Speed Drive.

With the implementation of the SVPWM variable speed drive, the inverter delivers six step current frequency pulse, which the voltage waveform follows. Switches in the inverter can be transistors, silicon controlled rectifier thyristors or gate turnoff thyristors. The pulse width modulation diode rectifiers provide constant DC voltage through a fixed DC to variable DC circuit (chopper). Since the inverter receives a fixed voltage, the amplitude of the output waveform of the DC bus voltage is also fixed. The inverter therefore adjusts the width output voltage pulses as well as frequency, so that the voltage is approximately sinusoidal.

Field voltage-controlled DC drives provide constant horsepower and variable torque as indicated in the screenshot interface of Figure 14. A variable voltage field regulator provides an alternate field voltage control. The motor speed is directly proportional to the voltage applied to the motor by the variable speed drive. A phase-controlled bridge rectifier with logic circuits is used with a tachometer feedback to achieve speed regulation. Comparing the variable speed drive to the fixed speed drive, the variable speed drive has more efficient control method, which saves energy and minimises total operating costs.

\section{Conclusion}

\subsection{Conclusions}

Inferences from data analysis indicate that, artisanal small scale gold mining in the Wassa East District is a serious phenomenon resulting in numerous disasters that includes: poor quality of abstracted raw water, and pump equipment deterioration in the study area.

The upstream deforestation contributes significantly to increased rates of sedimentation supply into the River Pra.

The paper has presented some useful information, which is expected to help improve water supply delivery in the study area. The SVPWM variable speed drive approach will minimise cost of operation, maintenance and equipment breakdown. The technique also optimised productivity and offered improvements and benefits over the existing equipment in spite of the prevailing illegal mining activities.

\subsection{Recommendations}

The following recommendations are made from the study and analysis:

(i) The SVPWM variable speed drive approach is recommended for replication in similar areas affected by these illegal mining activities to minimise unscheduled maintenance intervals;

(ii) That further research be conducted to improve pump efficiency strategy in the study area to reduce pumping cost;

(iii) That research be conducted on optimal on/off control model to minimise electricity cost at the study area; and

(iv) Finally, stiff regulations by the state would go a long way in addressing the serious environmental degradation within the River Pra, and most importantly, 
slow down the alarming rates of siltation and the deterioration of water quality and its availability to the study area.

\section{References}

[1] Bantay, K. (2012), “A Background Study on the Small-Scale Gold Mining Operations in Benguet and South Cotabato and their Impact on the Economy", Environment and the Community by The Alternate Forum for Research in Mindanao (AFRIM).

[2] Siduduziwe, P. (2012), "Artisanal small-scale mining: Potential Ecological disaster in Mzingwane District, Zimbabwe, Jamba" (Potchefstroom, South Africa), Vol 7, Issue 1, Doi: 10. 4102/jamba. v7i1. 158.

[3] Lawrence B. (1999), "Improving Pumping System Performance. A Sourcebook for Industry" The United States Department of Energy. Motor Challenge Program. In cooperation with: Hydraulic Institute, Parsippany, NJ.

[4] Guyer, J, P. E., (2012), "Introduction to Pumping Stations for Water Supply Systems", Continuing Education and Development. Inc. 9 Greyridge Farm Court Stony Point New York.

[5] Lawrence B. (2006), "Improving Pumping System Performance', A Sourcebook for Industry Second Edition." Renewable Energy Industrial Technologies Program.

[6] Anon. (2009), "Vertical Wet Pit Pumps" www. sulzer. com., Accessed: June 14, 2016.

[7] Papantonis, D. and Sahoo, T. (2012), "Strategies to Increase Energy Efficiency of Centrifugal Pumps", Mathura Refinery, India. ISBN: 978-953-51-0051-5.
[8] Tutterow, V. Hovstadius, G. and McKane, A. (2006), "Electrical Energy Equipment: Pumps and Pumping Systems" Energy Efficiency Guide for Industry in Asia. www. energyefficiencyasia. org., UNEP 2006.

[9] Peterson, H. (2012), "Poor Quality Raw Waters Need More than Chemical Treatment" Safe Drinking Water Foundation, www. safewater. org., Accessed: April 8, 2016.

[10] Sahoo, T. (2012), "Strategies to Increase Energy Efficiency of Centrifugal Pumps" M/S Indian Oil Corporation Ltd., Mathura Refinery, India.

[11] Ikonen, H. (2012), "An Improved Stochastic Optimization Model for Water Supply Pumping Systems in Urban Networks". www. optimization-online. org., Accessed: April 15, 2016.

[12] Hilson, G. (2002), "The Environmental Impact of Small-Scale Gold Mining in Ghana", Environmental Policy and Management Group (EPMG), Imperial College Centre for Environmental Technology.

[13] Hilson, G (2001), "A Contextual Review of the Ghanaian Small-scale Mining Industry", Imperial College Centre for Environmental Technology, www. pubs. iied. org/pdfs/G00722. Accessed: September 6, 2016.

[14] Nesbitt, B. (2006), "Handbook of Pumps and Pumping”, www. books.google.com/books/.../Handbook_of_Pumps_and_Pumpi ng, Accessed: October 18, 2016.

[15] Alem, D. and Vega, J. (2013), "An Improved Stochastic Optimization Model for Water Supply Pumping Systems in Urban Networks" Federal University of São Carlos, Rodovia João Leme dos Santos Brasil.

[16] Wiedenbrug, E. J. (2003), "Overheating Electric Motors: One Root Cause of Insulation Failure", A senior member to IEEE, $\mathrm{PhD}$ in electrical engineering from Oregon State University. 